\title{
Human Factor Risk Based Assessment For Roll On Roll Off Passenger Ferry Car Deck Fire Safety System
}

\author{
Sunaryo $^{a *}$ and Khaerunisa Sabitha ${ }^{b}$ \\ Naval Architecture And Marine Engineering Study Program, Universitas Indonesia, Depok, \\ Indonesia \\ a.naryo@eng.ui.ac.id,b.bithaanisa@gmail.com \\ *corresponding author
}

Keywords: $\quad$ fire safety; human factor; risks; roro ferry.

\begin{abstract}
The research is aimed to assess the fire safety system on the car decks of roll on roll off passenger ferry from the aspect of human factors as a part of efforts for assessing the safety system of national crossing ferries in Indonesia. Roll on roll off passenger ferry is the most accident vulnerable mode of water transports in Indonesia due to several of causes, one of them is fire. In roll on roll off passenger ferries fire might occur in many places, but according to recorded data it mainly occurs in engine room, car decks, and passenger decks. And it is also identified that human factor is the main cause of most of the fire accidents. For this purpose the research was conducted using Human Factor Analysis and Classification System method, where descriptive qualitative investigation of risk level and potential hazards were implemented in the assessment. Four types of hazards and four root causes of fire accidents were identified in the assessment.
\end{abstract}

\section{Introduction}

Crossing ferries play important role in connecting the more than 17,000 islands of Indonesia both for transporting goods as well as people, but due to some circumstances such as ship condition, crews qualification, passengers' behaviour, weather condition etc. accidents occur quite frequently, even some were very severe and claimed a number of human lives. Based on the accidents data recorded by the National Transportation Safety Committee (KNKT), Ministry of Transport Republic of Indonesia from 2010 to 2016 there was 54 ship accidents occurred and claimed 337 human lives [1]. The types and percentage of the accidents were identified as $35 \%$ due to explosion and fire; $31 \%$ due to collision; $24 \%$ due to sinking; $4 \%$ due to grounding, and $4 \%$ due to others causes, as shown on Fig. 1. KNKT also identified four main sources of accidents i.e. human factors; over loaded; technical factors; and weather condition, $80 \%$ of most of the accidents happened were caused by human factor, as stated in maritime world [2].

Results of the study on fire accidents happened on Ro-pax ferries conducted by DNV stated that source of fire were $63 \%$ originated from engine room; $27 \%$ from cargo and accommodation spaces, and 10\% from car decks [3], but according to data gathered from many sources showed that in Indonesia fire accidents occurred on crossing ferries mostly originated from ship's engine room and 
car decks, and the cause was mainly due to human factor both crews as well as passengers. It was also identified from previous studies that the background of those accidents were because during the crossing there were people (mainly truck drivers) remain in their vehicles and did not leave the car decks for their cargo's security reasons, and in case of the fire in the engine room were due to the messy and dirty condition of the engine room, and low competency of the crews [4].

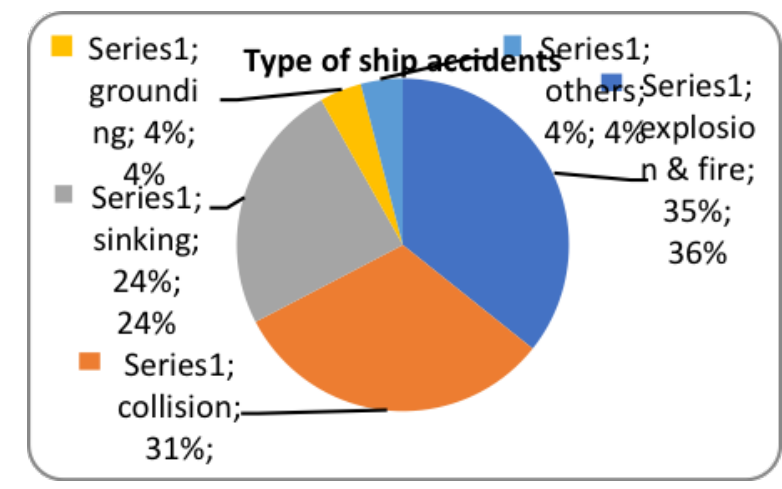

Figure 1: KNKT’s Ship Accidents Data 2010 -2016 (Source: KNKT)

Results of the study on fire accidents happened on Ro-pax ferries conducted by DNV stated that source of fire were $63 \%$ originated from engine room; $27 \%$ from cargo and accommodation spaces, and $10 \%$ from car decks [3], but according to data gathered from many sources showed that in Indonesia fire accidents occurred on crossing ferries mostly originated from ship's engine room and car decks, and the cause was mainly due to human factor both crews as well as passengers. It was also identified from previous studies that the background of those accidents were because during the crossing there were people (mainly truck drivers) remain in their vehicles and did not leave the car decks for their cargo's security reasons, and in case of the fire in the engine room were due to the messy and dirty condition of the engine room, and low competency of the crews [4].

Based on these findings the research was aimed to carry out assessment of the fire safety system on the roll on roll off ferries operated in Indonesian waters from the human factor aspects, and more specifically the study was focused on the fire occurred on the car decks, with the projected objective to improve the safety system of the national ferries.

\section{Methodology}

Descriptive qualitative approach was carried out in the study using obtainable data and information gathered from ro-pax crossing ferries operate on some busy routes in Indonesian waters, and from secondary resources, such as accidents data published by the National Transportation Safety Committee (KNKT), and news media. The assessment was carried out using Hazard Identification and Risks Assessment (HIRA), and Human Factor Analysis and Classification System (HFACS) methods.

The study was started by identifying primary hazards on the ferries' car decks and the potential influence of human factors on the hazards, then these potential contributions of human influences that might create accidents were investigated. Based on the findings of the investigation the levels of fire risks were analysed, continued with identifying the root causes of the risks. The risk levels were obtained by using risks level formula shown in (1), which states that risk is the result of the likelihood and the consequence of the event and presented in the form of risk level matrix as shown on Table 1. 


$$
\mathrm{R}=\mathrm{L} \text { X C }
$$

Where: $\mathrm{R}$ is risk level, $\mathrm{L}$ is likelihood, and $\mathrm{C}$ is consequence. Likelihoods are categorized as: rare, unlikely, possible, likely, and almost certain. Consequences are categorized as: Insignificant, Minor, Moderate, Major, and Extreme. Risk levels are categorized as: Low; Medium; High; and Extreme.

Table 1: Risk Matrix

\begin{tabular}{|c|c|c|c|c|c|}
\hline & \multicolumn{5}{|c|}{ CONSEQUENCE } \\
\hline LIKELIHOOD & 1. Insignificant & 2. Minor & 3. Moderate & 4. Major & 5. Extreme \\
\hline 1.Rare & 1.Low & 2.Low & 3.Low & 4.Low & 5.Low \\
\hline 2. Unlikely & 2.Low & 4.Low & 6.Low & 8.Medium & 10.Medium \\
\hline 3. Possible & 3.Low & 6.Low & 9.Medium & 12.Medium & 15.Medium \\
\hline 4. Likely & 4.Low & 8.Medium & 12.Medium & 16.High & 20.High \\
\hline 5. Almost certain & 5.Low & 10.Medium & 15.Medium & 20.High & 25.Extreme \\
\hline
\end{tabular}

\subsection{Fire Triangle}

As explained by National Fire Protection Association (NFPA) [5] fire is not a substance but a process of chemical reaction, an oxidation process between fuel, heath, and oxygen that happens very fast, which is known as Fire Triangle as shown in Figure 2. Fire releases energy and rises temperature, and in many cases produces smoke, toxic gas and waste, including fire's leftovers. NFPA also added another component to the fire triangle, which all together is called "fire tetrahedron" as shown in Figure 3, the uninhibited chain reaction of the feedback of heat to the fuel that produces gaseous fuel in the flame to maintain the fire. The heat energy transfers from the flame that spreads the fire through three different ways i.e. conduction, conviction, and radiation.

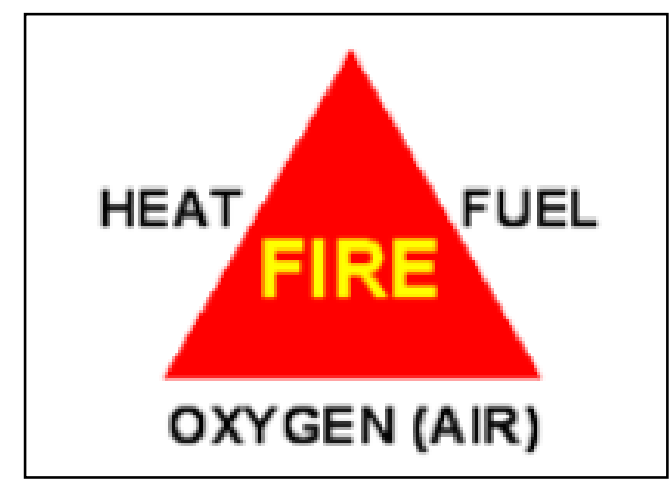

Figure 2: Fire Triangle (Source NFPA)

\subsection{Hazard Identification and Risk Assessment (HIRA)}

Hazard Identification and Risk Assessment (HIRA) is defined by the Ministry of Community Safety and Correctional Services Ontario Canada in Hazard Identification and Risk Assessment workbook [6] as: A tool for assessing risk to identify hazards that pose the greatest risk, which consist of the liklyhood they are to occur and the greatness of their potential impact. There are four steps to conduct a HIRA:

- Hazard Identification

- Risk Assessment

- Risk Analysis

- Monitor and Review 


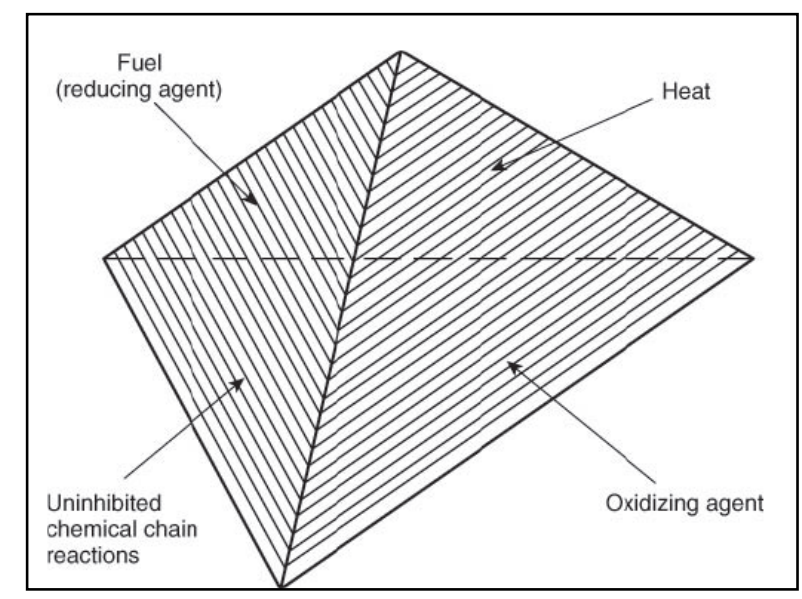

Figure 3: Fire Tetrahedron (Source NFPA)

\subsection{Human Factor Analysis and Classification System (HFACS)}

Health and Safety Executive (HSE) [7] defines human factors as the influence of working behavior to the health and safety through environment, organization and job, and human and individual characteristics. Human factor involves three interrelated aspects i.e. the job, individual characteristics, and organization. The job consists of: the nature of the task, workload, working environment etc., the individual characteristics includes: competence, skills, personality, attitude, and risk perception, the organization includes: work patterns, the workplace culture, resources, communications, leadership etc.

HSE states that human failures have potential to cause or contribute to accidents. The consequences of human failures to accident can be direct or indirect. Active failures have direct consequence and are usually made by frontline people. Indirect failures are usually hidden within an organization until they are triggered by an event likely to have serious consequences. Indirect failures are usually created by people whose tasks are removed in time and space from operational activities.

Reason [8] suggests that the problems of human error can be approached from two points of view: the person approach and the system approach. The person approach is focused on the unsafe acts, and procedural violations as the results of mainly from unusual mental processes such as absentmindedness, lack of concentration, lack of motivation, inattention, negligence, and recklessness. The system approach assumes that humans are fallible and errors are to be expected, even in the best organization, errors are seen as consequences rather than causes. Human Factor Analysis and Classification System (HFACS) [9] was developed by Wiegmann and Shappell, two behavioral scientists in the Unites States Navy as framework for investigating accident, as the supplement to HFACS Soner, Asan, and Celik [10] suggest that the system should use four classifications of failure to identify the root causes of the accident i.e.: unsafe acts, preconditions for unsafe acts, unsafe supervision, and organizational influences.

\subsection{Root Cause Analysis}

The root cause analysis of the potential fire risks was conducted using Human Factor Analysis and Classification System (HFACS). For the purposes of analysing the root cause, each root cause classification is assigned a particular number as shown in Table 2, 3, 4, and 5. 
Table 2: Root Causes of Unsafe Acts

\begin{tabular}{|c|l|}
\hline Root Cause & Activity \\
\hline C1 & Fail to give response to operational failure \\
\hline C2 & Panic in responding to the fire accident \\
\hline C3 & Fail to follow fire safety procedures \\
\hline C4 & Ignore in doing routine fire safety inspection \\
\hline C5 & Misunderstanding to the fire safety procedures \\
\hline C6 & Violating on board fire safety drilling \\
\hline C8 & Ignore to the components of safety culture \\
\hline C9 & In disciplinary of the fire safety team \\
\hline & Ignoring information due to bad communication system \\
\hline
\end{tabular}

Table 3: Root Causes of Preconditions for Unsafe Acts

\begin{tabular}{|c|l|}
\hline Root Cause & Activity \\
\hline C10 & Loss of situational awareness \\
\hline C11 & Lack of motivation of crews on board \\
\hline C12 & Psychological unfit states of the crews on board \\
\hline C13 & Unfamiliar to fire safety requirement \\
\hline C14 15 & Over confidence of the crews to the situation \\
\hline C16 & Physical exhaustion of crews \\
\hline C17 & Time constraint to react to the fire situation \\
\hline C18 & Incompetence of crews to fire safety \\
\hline C19 & Insufficient physical capability in emergency response \\
\hline C20 & Unable to coordinate during emergency condition \\
\hline C21 & Failed to conduct operational planning and briefing \\
\hline C22 & Lack of fire safety warning and signaling system \\
\hline C23 & Lack of safety attitudes due to health problems \\
\hline & Emotional overload of crews \\
\hline
\end{tabular}

Table 4: Root Causes of Unsafe Supervisions

\begin{tabular}{|c|l|}
\hline Root Cause & Activity \\
\hline C24 & Failed to give guidance for fire prevention system \\
\hline C25 & Failed to provide appropriate fire fighting drill \\
\hline C26 & Failed to allocate qualified crews on board \\
\hline C27 & Unable to continuously monitoring crew performance \\
\hline C28 & Failed to provide appropriate crew resting time \\
\hline C29 & Failed to identify fire related hazards on board ship \\
\hline C30 & Failed to ommence fire safety corrective actions \\
\hline C31 & Failed to report unsafe fire prevention action \\
\hline C32 & Lack of conducting fire safety assessment program \\
\hline C33 & Lack of communication between supervisor and crews \\
\hline
\end{tabular}

Table 5: Root Causes of Organizational Influences

\begin{tabular}{|c|l|}
\hline Root Cause & Activity \\
\hline C34 & Lack of company integrated safety policy \\
\hline C35 & Poor personnel recruitment procedures \\
\hline C36 & Poor shore-based personnel management system \\
\hline C37 & Insufficient crew training program \\
\hline C38 & Lack of up dating policy to monitor safety procedures \\
\hline C39 & Ineffective fire safety communication system. \\
\hline C40 & Confusing fire control policy \\
\hline C41 & Excessive time pressure \\
\hline C42 43 & Ineffective risk control system \\
\hline & Lack of safety continuous improvement \\
\hline
\end{tabular}




\section{Results}

\subsection{Hazard Identification}

Sunaryo, Nugroho, and Talahatu [9] in their previous study identified that the three components of fire triangle that exist on the car decks of ro-pax ferries among other things are: as the fuel for the fire includes: the fuel of vehicles parked on the deck, the cargo carried in the vehicles, inflammable materials of the vehicles; as heat source are the engines of the vehicle, and in some cases sparks of fire due to short circuit of electricity connections; and the oxygen is the air blow from the ventilation system of the car decks.

Results obtained from the on the spot investigation and interviews, literature studies, and discussions with experts suggested that the human factors which might cause fire hazards on the ropax ferries' car decks are:

- Drivers and or assistants stayed in the vehicles and did not go to the passenger decks during the crossing time in order to watch for the security of their cargo,

- Engines of the vehicles were on during the crossing time in order to keep the air conditioning in the vehicles on so that the drivers could conveniently stay in the vehicles,

- Passengers smoked on the car decks or threw cigarette butt improperly during the crossing, before leaving the car decks, or when entering the car decks,

- Crews did not check the car decks and their equipment properly before the ferries left the port, due to the limitation of time available for vehicles embarkation,

- Improper inspection and maintenance of the fire safety equipment on the car decks,

- Crews ignorant in implementing safety regulations.

The potential hazards that might trigger fire accidents are:

- Fire from the live cigarette butt ignites the fuel of the vehicles parked on the car decks,

- Heat develops from the vehicles' engine increases the potential creation of fire triangle,

- Short circuit of improper electricity connections might trigger sparks and initiate fire,

- Fire safety equipment might not work properly when they are needed.

\subsection{Risk Assessment and Analysis}

In order to investigate the risk level of each potential hazard and its root causes the likelihood of the hazards are categorized as shown in Table 6, and the consequences are shown in Table 7, and the grouping of root causes into their consequences are presented by HFACS adjacency matrix in Table 8.

Referred to the likelihood and consequence tables the risk level of each hazard was obtained using (1) and categorized as shown in Table 1, and the root causes of each risk level were identified using HFACS adjacency matrix. Results of the assessment can be used by the stakeholders to justify the safety of the ship and further actions could be taken in accordance to the existing safety standards and regulations.

Table 6: Likelihood

\begin{tabular}{|c|l|l|}
\hline Value & \multicolumn{1}{|c|}{ Likelihood } & \multicolumn{1}{c|}{ Likelihood Criteria } \\
\hline 5 & Almost certain & Fire occurred every month \\
\hline 4 & Likely & Fire occurred every 6 months \\
\hline 3 & Possible & Fire occurred every year \\
\hline 2 & Unlikely & Fire occurred between 1 -5 years \\
\hline 1 & Rare & Fire occurred more than 5 years \\
\hline
\end{tabular}


Table 7: Consequences

\begin{tabular}{|c|l|l|}
\hline Value & \multicolumn{1}{|c|}{ Consequence } & \multicolumn{1}{c|}{ Consequence Criteria } \\
\hline 5 & Extreme & Fatal, can cause death or permanent injury \\
\hline 4 & Major & Injury more than 30 days off \\
\hline 3 & Moderate & Injury between 10 - 30 days off \\
\hline 2 & Minor & Injury between 3 - 10 days off \\
\hline 1 & Insignificant & Injury less than 3 days off \\
\hline
\end{tabular}

Table 8: HFACS Adjacency Matrix

\begin{tabular}{|c|c|c|c|c|}
\hline & UA & PUA & US & OI \\
\hline Extreme & $\begin{array}{c}\mathrm{C} 1, \mathrm{C} 3, \mathrm{C} 4, \mathrm{C} 6 \\
\mathrm{C} 7\end{array}$ & $\begin{array}{c}\mathrm{C} 10, \mathrm{C} 15, \mathrm{C} 17 \\
\mathrm{C} 18, \mathrm{C} 20\end{array}$ & $\begin{array}{c}\mathrm{C} 26, \mathrm{C} 27, \mathrm{C} 28 \\
\mathrm{C} 32\end{array}$ & $\mathrm{C} 34, \mathrm{C} 35$ \\
\hline Major & $\mathrm{C} 2, \mathrm{C} 5$ & $\begin{array}{c}\mathrm{C} 11, \mathrm{C} 12, \mathrm{C} 16, \\
\mathrm{C} 19, \mathrm{C} 21, \mathrm{C} 22, \\
\mathrm{C} 23\end{array}$ & $\mathrm{C} 24, \mathrm{C} 25, \mathrm{C} 29$ & $\begin{array}{c}\mathrm{C} 36, \mathrm{C} 38, \mathrm{C} 42, \\
\mathrm{C} 43\end{array}$ \\
\hline Moderate & $\mathrm{C} 8, \mathrm{C} 9$ & $\mathrm{C} 13, \mathrm{C} 14$ & C30, C31, C33 & C37, C40 \\
\hline Minor & & & & C3 9, C41 \\
\hline Insignificant & & & & \\
\hline
\end{tabular}

Where: UA is unsafe acts, PUA is pre-conditions for unsafe acts, US is unsafe supervision, OI is organizational influences.

Refer to risk level shown in Table 1 the risk categories are grouped as follows: extreme with risk level 25, where the risk might cause loss of life and total loss of property, and the occurrence is mostly certain; high with risk level 16 to 20, where severe injury might occur to people and fatal damage to property, and the probability near certain; medium with risk level 8 to 15 , where the fire involving danger to person(s) and damage to property, and probability of occurrence reasonably likely; low with risk level 1 to 6 , where the fire at the most only causing minor injury to person(s) and insignificant damage to property, and the occurrence is never or seldom.

\subsection{Application of The Assessment}

For immediate application the assessment could be conducted by the safety officer and the crews assigned on board to ensure the safety of the ferry, with the requirements that:

- The safety officer possesses sufficient knowledge of ISM code, and requirements of crews according to STCW 95,

- The safety officer possesses sufficient knowledge of basic safety training for prevention and combating fire accident on board the ship, including survival, basic fire prevention and firefighting,

- The safety officer knows the detail duties of the crews assigned on the car decks,

- The safety officer possesses sufficient knowledge of and capable to carry out Human Factor Analysis and Classification System (HFACS),

- The safety officer will be provided with HFACS adjacency matrix, so that he/she could make appropriate decision for action,

- The safety officer should assess the competency of the crews assigned on the car decks,

- The safety officer is given authority to conduct car decks fire safety assessment based on the points provided in the HFACS. 
Results of the assessment are then used as the reference for arranging safety measure to be applied on board as part of the managements' safety policy.

\section{CONCLUSIONS}

Based on the data and information gathered, and the assessment being carried out in the study, it is concluded that:

- Human factors play highest roles in the potential occurrence of fire accidents on board ro-pax ferries in Indonesia.

- Four hazards and four root causes were identified that might initiate fire on the ro-pax ferry car decks.

- Risk levels of the identified hazards could be obtained using the proposed risk assessment and analysis method.

- Root causes of potential fire accidents on the ro-pax ferry car decks were obtained using Human Factor Analysis and Classification System (HFACS) method.

\section{Acknowledgements}

The authors appreciate the management of PT Indonesian Ferries for granting permission to conduct survey and site visits, and providing invaluable data and information for the study, and express gratitute to the Ministry of Research Technology and Higher Education Republic of Indonesia for the research fund to carry out the study, and to the Directorate of Research and Community Engagement Universitas Indonesia for facilitating in obtaining the research funding.

\section{References}

[1] National Committee for the Safety of Transport, (2016) Ship Accidents Investigation Data 2010 - 2016" (Data Investigasi Kecelakaan Pelayaran 2010 - 2016), Media Release KNKT.

[2] Dunia Maritim, The Causes of Hihg Ship Accidents Rate in Indonesia (Penyebab Tingginya Angka Kecelapaan Kapal di Indonesia), Dunia Maritim.id, 2017, https://duniamaritim.id, 27 April 2017.

[3] Det Norske Veritas, Fires On Ro-Ro Decks, DnV Technical Paper, Paper series no. 2005-p018, September 2005.

[4] Sunaryo, and A I. Azhary, Analysis on the Effectiveness of Fire Safety Equipment in Resisting the Spread of Heat and Smoke During Fire Accident on Roro-pax Crossing Ferry (Case Study on Local Indonesian Ferry),

Proceedings of Fire at Sea International Conference, Royan Institution of Naval Architects, 26 - 27 March 2014 , pp $77-86$.

[5] National Fire Protection Association, (2018) All About Fire, Reporter's Guide, NPFA.org.

[6] Ministry of Community Safety and Correctional Services, (2016) Hazard Identification and Risk Assessment, Workbook, Ontario Canada.

[7] Health and Safety Executive, Introduction to Human factors, http://www.hse.gov.uk/humanfactors/introduction.htm

[8] J. Reason, Human Error Models and management, British Medical Journal, Vol. 320, 2000, pp 768 - 770.

[9] Sunaryo, Nugroho Y, Talahatu A. M, (2013) Onboard Fire Safety Assessment Standards for Indonesian Non Convention Roll On Roll Off Passenger Ferries. Jurnal Teknologi, Vol. 65 No. 1, pp 83 - 91.

[10]O. Soner, U. Asan, M. Celik, (2015) Use of HFACS-FCM in fire prevention modelling on board ships, Safety Science, Vol. 77, pp $25-41$. 